\title{
Assessment of Motor Functioning in the Preschool Period
}

Jan P. Piek ${ }^{1}$, Beth Hands ${ }^{2} \&$ Melissa K. Licari ${ }^{3}$

${ }^{1}$ School of Psychology and Speech Pathology, Curtin Health Innovation Research Institute, Curtin University, GPO Box U1987, Perth 6845, Western Australia

${ }^{2}$ Institute for Health and Rehabilitation Science, University of Notre Dame Australia, PO Box 1225, Fremantle 6959, Western Australia

${ }^{3}$ School of Sport Science, Exercise \& Health, The University of Western Australia, 35 Stirling Highway, Crawley 6009, Western Australia

Corresponding Author: Professor Jan Piek

Email: j.piek@curtin.edu.au

Tel: +61892667990

Fax: +61892662464 


\begin{abstract}
The assessment of motor functioning in young children has become increasingly important in recent years with the acknowledgement that motor impairment is linked with cognitive, language, social and emotional difficulties. However, there is no one gold standard assessment tool to investigate motor ability in children. The aim of the current paper was to discuss the issues related to the assessment of motor ability in young pre-school children and to provide guidelines on the best approach for motor assessment. The paper discusses the maturational changes in brain development at the preschool level in relation to motor ability. Other issues include sex differences in motor ability at this young age, and evidence for this in relation to sociological versus biological influences. From the previous literature it is unclear what needs to be assessed in relation to motor functioning. Should the focus be underlying motor processes or movement skill assessment? Several key assessment tools are discussed that produce a general measure of motor performance followed by a description of tools that assess specific skills, such as fine and gross motor, ball and graphomotor skills. The paper concludes with recommendations on the best approach in assessing motor function in pre-school children.
\end{abstract}

\title{
Keywords
}

Motor ability, movement skill, motor assessment, preschool children, fine motor, gross motor, grapho-motor skills 


\section{Introduction}

In the last decade, there has been an increasing acknowledgment in the child development literature of the importance of motor ability in a child's overall development, particularly if this is compromised. Motor impairment often accompanies disorders such as autism (e.g., Dewey, Cantell, and Crawford 2007; Dyck, Piek, Hay, Smith and Hallmayer 2006), attention deficit hyperactivity disorder (ADHD) (e.g., Pitcher, Piek and Hay 2003; Rasmussen and Gillberg 2000), learning disabilities such as dyslexia (Fawcett and Nicholson 1995), and anxiety disorders (Erez, Gordon, Sever, Sadeh and Matti, 2004). Motor impairment may also be categorised as a disorder in its own right, ranging from severe motor impairment seen in cerebral palsy, to the relatively mild seen in children with Developmental Coordination Disorder (DCD), a condition defined as "a marked impairment in the development of motor coordination that significantly interferes with academic competence or daily living skills" (American Psychiatric Association, 2000, p. 56).

Research has recently highlighted the importance of addressing mild motor impairment because of the co-occurring difficulties that often accompanies this. There is evidence that poor motor ability may impact on physical fitness (Chia, Guelfi and Licari 2009; Hands and Larkin 2002, 2006; Silman, Cairney, Hay, Klentrou and Faught 2011), with the potential for the child to be overweight or obese (Hands, Larkin, Parker, Straker and Perry 2009). This may result in increased risk of cardiorespiratory disease (Schott, Alof, Hultsch and Meermann 2007). There may also be accompanying difficulties in academic (Alloway 2007; Dewey, Wilson, Crawford and Kaplan 2000), social (Smyth and Anderson 2000) and emotional (Cairney, Veldhuizen and Szatmari 2010; Rigoli, Piek and Kane 2012) functioning. For instance, children with DCD have been found to withdraw and avoid motor activities (e.g., Mandich, Polatajko and Rodger 2003), have poorer self-perceptions and self- 
worth (e.g., Miyahara and Piek 2006; Rose, Larkin and Berger 1997; Skinner and Piek 2001), and are more likely to have higher levels of anxiety (Pearsall-Jones, Piek, Rigoli, Martin and Levy 2011; Skinner and Piek 2001) and depression (Piek, Rigoli, Pearsall-Jones, Martin, Hay, Bennett et al. 2007), even in preschool children as young as 4 years of age (Piek, Bradbury, Elsley, and Tate 2008). Furthermore, longitudinal studies have identified a relationship between early motor ability on later cognitive (e.g., Murray et al. 2006; Piek, Dawson, Smith and Gasson 2008), academic (e.g., Kurdek and Sinclair 2001), and emotional (e.g., Piek, Barrett, Smith, Rigoli and Gasson 2010; Sigurdsson, van Os and Fombonne 2002) outcomes. Therefore, early identification of motor impairment is important to ensure that the child has the appropriate support, particularly prior to commencing school, where the additional pressures of their poor motor performance may have deleterious effects on cognitive, academic and social-emotional development.

What is unclear at pre-school age is whether poor performance in the motor domain is attributable to specific impairment such as cerebral palsy or DCD, or whether it is a result of delayed development possibly due to a lack of opportunity to learn or practice motor skills (Gottlieb 2001). Prior motor experience has been identified for many decades as an important factor in motor development, as highlighted by Bower's (1977) comment that "it seems clear that the environment-initiated opportunities for practice in fact have a great deal to do with both the rate and direction of motor development" (p. 91). This early motor experience begins during the fetal stage (e.g., Provine 1993), and considerable research in the area of postural control has highlighted its importance in infancy (e.g., Haas and Dienar 1988; Sveistrup and Woolacott 1996, 1997). Hence a child has had considerable opportunity for experience and practice with motor skills by the time they reach preschool age.

The early years are a very rapid stage of development, marked by considerable growth and change in a child's motor repertoire. In the first instance, young children learn the pattern 
of basic movements before refining their performance and combining these movements into complex skills needed for activities of daily living and participation in many different types of physical activity. For example, once children have mastered the leap and hop they can combine these to perform a basketball lay-up. The age children master skills varies, but in general, most fundamental movement skills are in place by 8 years of age. Contributing to this rapid development are changes occurring at the neurological level, with more than 100 billion neurons intricately connecting with one another and undergoing constant alteration to enable one to execute the many functions underlying human motor behaviour. While many changes are genetically predetermined, there are also critical periods or "windows of opportunity' where neurodevelopment is affected by quality of the child's environment (Chugani 1998; Greenough and Black 1992), particularly in early childhood. For example, children who are exposed to stimulating environments that are supportive of skill development are more likely develop into confident and proficient movers. While children who are constrained or discouraged to be active, with limited social interaction, do not have the opportunity to expand their motor repertoire and develop confidence in their own ability (Goodway, Crowe and Ward 2003; McPhillips and Jordan-Black 2007).

\section{Brain Development in Young Children}

Over the past two decades, neuroimaging studies have contributed considerably to our knowledge of maturational changes occurring during brain development which coincide with marked improvements in cognitive, motor and perceptual abilities (see Casey, Tottenham, Liston and Durston 2005 for a review). Despite brain size only growing from $80 \%$ to $90 \%$ of its adult size between 2 and 5 years of age (Dekaban 1978), there are many changes occurring at the cellular level as a result of myelination, synaptic remodelling and pruning (Tau and Peterson 2010). The extent of this activity is highlighted in studies which have demonstrated 
that resting brain glucose metabolism is at its highest in early childhood, almost twice that of adult levels in 4 to 5 year old children (Chugani 1994; Chugani, Phelps and Mazziota 1987).

It is well documented that the increase in brain volume during childhood is not uniform, with variable periods of growth in different regions of the cerebral cortex (Johnson 2003). Sensory and motor areas are typically the first to mature (Casey et al. 2005), with the density of synapses in the sensorimotor cortex reaching adult levels between late infancy and the pre-school period. However, motor control is dependent on many interconnections between cortical and sub-cortical regions of the brain. For example, the prefrontal and lateral temporal cortices, important for integrating the primary sensory-motor processes and higher cognitive functions, do not appear to reach adult levels of maturity until adolescence. Despite long developmental times, these regions do undergo the most dramatic annualised rate of change during childhood. This was demonstrated in work by Sowell, Thompson, Leonard, Welcome, Kan and Toga (2004) who found that the brain expands up to 1mm a year in the prefrontal cortex in children aged 5-11 years (see Fig. 1). Interestingly, during these critical periods of brain development, abnormalities in behaviour and motor functioning become most evident. This demonstrates that many brain functions involve highly sophisticated cortical networks and an abnormality or delay in the development in one area is likely to impact the functioning of another.

\section{Insert Fig 1 about here}

As a result of these varying maturational rates, different motor processes are likely to mature at different rates, and this needs to be taken into account when considering the assessment of motor performance. As Hayes and Martenuik noted (in Fietzek et al 2000), the neural control mechanisms involved in the performance of particular motor skills may define their complexity. Largo and colleagues (2001) identified complexity as a key issue in relation to developmental trajectories for different timed movements. They criticised earlier 
neurological assessment tools for not taking into account task complexity and maturational differences, and recommended that the measurement of motor performance should take a development-oriented approach as is the case for intellectual performance, where "agespecific changes and inter-individual variation has been a well-accepted practice for many years" (p.435). Consequently, they produced normative data for tasks requiring timed performance such as repetitive and sequential finger movements, pegboard tasks, alternating hand and foot movements, and static and dynamic balance tasks in children aged between 5 and 18 years. In all tasks, performance improved throughout the pre-pubertal period, with complexity of the movement impacting on the rate of improvement and the age at which the movement reached its best performance. As a result of this study, the authors recommended that assessment of motor performance requires age-specific standards for specific motor tasks.

\section{Sex Differences in Motor Ability}

Although there has been evidence in the research literature for over half a century of sex differences in motor ability (Gutteridge, 1939; Morris, Williams, Atwater, \& Wilmore, 1982; Thomas \& French, 1985), this has been largely ignored in the development of motor assessment tools for young children. In 1976, Touwen identified 'appreciable' differences between boys and girls in terms of the development of their motor milestones in infancy. $\mathrm{He}$ found that boys appeared to walk or sit earlier than girls, whereas girls developed functional skills such as vocalising and grasping sooner. Others have also identified sex differences in motor performance in infants and children; boys usually better at locomotor skills and girls better at balancing skills and flexibility tasks (e.g., Anastasi 1981; Capute, Shapiro, Palmer, Ross and Wachtel 1985; Hands \& Larkin, 1997; Pedersen, Sigmundsson, Whiting and 
Ingvaldsen 2003; Piek, Gasson, Barrett and Case 2002; Thomas and French 1985; Van Waelvelde, De Weert, De Cock and Smits-Engelsmen 2003).

Motor tests such as the McCarron Assessment of Neuromuscular Development (MAND: McCarron 1997) have acknowledged different motor abilities for adolescent males and females following puberty, and included separate norms from age 14 years. These differences in adolescence are supported by the results of imaging studies investigating brain morphology in adolescence. For example, Groeschel, Vollmer, King and Connelly (2010) found a larger white matter volume and a greater increase in the white matter to grey matter ratio in adolescent males compared with females. Perrin et al. (2009) suggested that these differences may be due to increased axonal calibre in males and an increase in myelination in females.

However, the failure of most tests to account for sex differences among younger children is a concern. Thomas and French (1985) suggested that these differences may be due primarily to sociological factors. That is, boys are more likely to do better at skills such as running, jumping and catching, and girls at fine motor skills due to more practice and experience as a result of gender stereotyping. However, there is considerable neurological evidence of differences between boys and girls in brain structure and function from infancy (e.g., de Bellis et al. 2001; Liu et al. 2011), suggesting that biological factors may also be linked with the sex differences identified. For example, Liu and colleagues used MR imaging to investigate sex differences in 19 male and 19 female healthy preterm neonates. The total brain volume was investigated in 38 infants and was found to be $10.7 \%$ larger for boys (mean $\left.\pm \mathrm{SD}, 461 \pm 59 \mathrm{~cm}^{3}\right)$ compared with girls $\left(414 \pm 30 \mathrm{~cm}^{3}\right)$, although white matter tract volumes were significantly larger in girls than boys (see Fig. 2). They identified sex differences in language and motor related tracts, and suggested that this may be due to genetic factors or a result of the impact of sex steroids on early brain development. However, given that this 
study used healthy preterm infants at term-equivalent age, the authors suggest that the results be treated with caution as further studies are required to determine whether these early structural differences between boys and girls are linked with later sex differences in motor and language functioning. Despite this caution, it is clear that there is considerable evidence to suggest that when motor assessment tools are developed, possible sex differences need to be considered at all ages, not just during the adolescent period.

Insert Fig. 2 about here

\section{Motor Assessment Tests}

There are dozens of assessment tools available to examine motor performance at the preschool age. Many of these tools were developed last century but only the more popular tests that have been developed or updated in the last 20 years will be described here. It is essential that the norms for these assessment tools are regularly updated as there is evidence for a trend of earlier onset of common motor milestones more recently compared with earlier in the last century (e.g., Capute et al. 1985; Gallahue and Ozmun 2002; Piek 2006). There are many factors that could contribute to this, although changes in child-rearing practices may be a major factor given that research has identified cultural differences in child-rearing resulting in different rates of motor milestone development (e.g., Hamilton 1981; Super 1976). In contrast, Blank and colleagues (2012) warn that over the last 40 years there has been a "downward trend in motor ability" (p. 72), and urge that tests maintain up to date norms as a result.

\section{General motor assessment}

Many of the motor assessment measures produce a total assessment score similar to intelligence tests, which give an indication of the child's overall motor performance in relation to children of the same age. This implies that there is a single trait for motor ability, a 
general motor ability (GMA), which is a contentious issue. Despite the arguments against this, Burton and Rodgerson (2001) argue that "the overall composite scores in most movement assessment instruments provide at least rough estimates of GMA” (p. 362). Therefore these tests serve a purpose. However, unlike intelligence and language assessments, no one motor test has been identified as a gold standard assessment tool.

Extensive literature is available that evaluates the more commonly used tests, but most of this relates to earlier test versions. Many of the problems with these tests raised in the literature have been addressed in the more recent versions, and therefore only literature relating to the new editions will be considered in relation to the evaluation of the tests.

Several recent reviews (e.g., Brown and Lalor 2009; Cools, De Martelaer, Samaey and Andries 2009; Slater, Hillier and Civetta 2010; van Hartingsveldt, De Groot, Aarts and Nijhuis-van der Sanden 2011) provide comprehensive descriptions of the most commonly used assessment tools. Four of these tests are briefly outlined below.

\section{Movement Assessment Battery for Children $\left(2^{\text {nd }}\right.$ Edition $)-($ MABC-2) This test by}

Henderson, Sugden and Barnett (2007), a revised version of the Movement Assessment Battery for Children (Henderson and Sugden 1992), has been described as one of the most commonly used tests of motor impairment by health practitioners (e.g., Geuze, Jongmans, Schoemaker and Smits-Engelsman 2001). It has 8 items divided into aiming and catching (2 items), manual dexterity (3 items) and static and dynamic balance (3 items), each of which produce a component standard score in addition to a total standard score. The MABC-2 has three different age bands of 3-6, 7-10 and 11-16 years and is therefore suitable for preschool children. Testing time is generally between 20 and 40 minutes.

Although the original MABC demonstrated excellent reliability and validity, very few studies have been published for the $2^{\text {nd }}$ edition. Smits-Engelsman, Niemeijer and van Waelvelde (2011) reported reasonable reliability for the MABC-2 in a small study of 50 
children aged 3 years. Brown and Lalor (2009) also report an unpublished study by Visser and Jongmans (2004) prior to the release of the MABC-2 where test-retest reliability was found to be between 0.49 and 0.70 in a sample of 55 3-year old children. The test authors report correlations between .86 and .91 for test-retest reliability in a sample of 203 -year old children. Smits-Engelsman and colleagues noted that even when young children were unable to perform the tests as described in the instructions, test results remained highly reproducible, supporting the use of this test in young children. One criticism of the MABC-2 is that despite evidence that the original MABC test produced different results for boys and girls in the lower age ranges (e.g. Engel-Yeger, Rosenblum and Josman 2010; Livesey, Coleman and Piek 2007), separate norms for boys and girls were not considered necessary (Barnett, 2008). A further criticism is that because test items and scaling differ between age bands, this may cause difficulties with the longitudinal analysis of individuals, either for research purposes or in ongoing clinical evaluation (Blank et al. 2012). Despite these concerns, the MABC-2 remains one of the most popular assessment tools due to its sound psychometric properties and ease of use which requires minimal training. Slater and colleagues (2010) ranked it the highest in their evaluation of seven different tests, although they cautioned that further evaluation of its psychometric properties is required.

$\underline{\left.\text { Peabody Developmental Motor Scales ( } 2^{\text {nd }} \text { Edition }\right)}$ - (PDMS-2) According to Cools and colleagues (2009), the PDMS-2 (Folio and Fewell 2000) has changed very little from the original PDMS (Folio and Fewell 1983), with an update of normative data for American and Canadian children, and a more thorough analysis of reliability and validity. The PDMS-2 is suitable for infants and children aged from birth to 5 years 11 months, so is not suitable for ongoing assessment into the school years. This could be considered a limitation in follow-up assessment and also in research comparing pre-school children with older children. It is also quite lengthy to administer taking from 45 to 60 minutes. Although it provides separate 
measures for gross and fine motor performance, and has been found to have good reliability and validity, Slater and colleagues (2010) ranked this test $5^{\text {th }}$ out of the seven tests evaluated. A particular concern noted by Slater et al. was the lack of sensitivity in identifying children with minor motor deficits.

\section{Bruininks-Oseretsky Test of Motor Proficiency ( $2^{\text {nd }}$ Edition $)-($ BOT-2). The BOT-2} (Bruininks and Bruininks 2005) is a revised version of the BOTMP (Bruininks 1978). One specific aim of the revised version was to "improve measurement among 4- and 5-year-olds" (p.1) by extending the target range downwards. Consequently, new activities were included and others modified. The long (or complete) version now comprises 53 items (7 more than the original BOTMP) and 14 items in the short form. In contrast with the PDMS-2, the BOT2 was designed to "identify motor skill deficits in individuals with mild to moderate motor control problems" (p.1). A further advantage of this test is that age and gender specific norms are provided for individuals from 4 to 21 years of age. However, the test time of 40 60 minutes is long, particularly for young children, and the score conversion system is quite complicated.

The BOT-2 provides results for eight subtests measuring fine motor precision, fine motor integration, manual dexterity, bilateral coordination, balance, running speed and agility, upper limb coordination, and strength, which are aggregated into fine manual control, manual coordination, body coordination and strength and agility composites. The sum of all scores results in a total composite score. Evidence is provided for the content and construct validity, and test-retest and interrater reliability of the test for 4 years olds is provided. Slater et al. (2010) ranked this test as $3^{\text {rd }}$ out of 7. Deitz, Kartin and Kopp (2007) found that some test items are still quite difficult for typically developing 4 year olds and for 5 year olds with developmental delay. When the lengthy test time is also considered, this test is most appropriate for children aged 6 years and upwards. There is, however, a short form of the 
BOT-2 which may be more suitable for the assessment of the younger children. However, few studies have examined its psychometric properties in pre-school aged children.

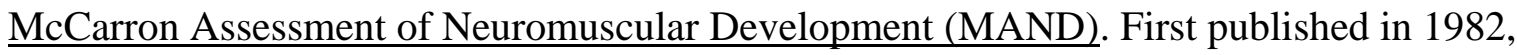
the MAND (McCarron 1997) is designed to measure a broad spectrum of motor performance in individuals aged from $31 / 2$ years to adulthood. While a second edition of the manual was released in 1997, minimal changes were made. Sex-specific scaled scores were included for two strength tasks (hand strength and jump) for individuals from 14 years of age. The ten item test, which includes both fine and gross motor activities, and measures abilities such as one and two hand dexterity, static and dynamic balance and postural control, takes approximately 15-20 minutes to administer. Items are scored quantitatively, qualitatively or a combination of both. The raw scores are converted to age-adjusted scaled scores $(M=10$, $\mathrm{SD}=3$ ) which are summed and normalised to create a Neuromuscular Developmental Index $(\mathrm{M}=100, \mathrm{SD}=15)$.

Evidence is provided by McCarron (1997) of the content, construct, predictive and concurrent validity and test-retest reliability of the MAND. It appears that only two other studies have examined the psychometric properties of the MAND, both Australian (Brantner, Piek and Smith 2009; Tan, Parker and Larkin 2001). Its validity as a measure of motor impairment with young children (4- 6 years) has been questioned (Brantner et al 2009) although Tan and colleagues (2001) found it to be a more accurate identifier of children (5 11 years) with motor impairment compared to the BOTMP. Slater et al. (2010) considered some of the test items as unusual and the scoring system as difficult to interpret. The authors ranked this test as equal lowest with the Zurich Neuromotor Assessment which is primarily used in Switzerland (Blank et al. 2012). 


\section{Overview}

It can be seen from the above list that some of these tests are described as measuring motor and others, movement performance. According to Keogh and Sugden (1985), the term 'motor' is indicative of an internal process and is often linked with motor ability, defined by Burton and Miller (1998) as "general traits or capacities of an individual that underlie the performance of a variety of movement skills" (p.43). The term 'movement', on the other hand, refers to skills that are external and observable, namely, "a specific class of goaldirected movement patterns such as running, throwing, hammering, driving, writing, or even speaking" (Burton and Miller 1998, p.44). However, as not all test developers have this understanding, it is important to ask, do these listed tests measure observable motor skills or are they assessing the underlying motor abilities? And what should they be testing? (Burton and Rodgerson 2001).

Studies that have compared these tests have often found quite different results for the children tested (e.g., Brantner et al. 2009; Spironello, Hay, Missiuna, Faught and Cairney, 2010; Tan et al. 2001). Both Spironello and colleagues, and Tan and colleagues found poor agreement in terms of motor competence between the original version of the short form Bruininks-Oseretsky Test (Bruininks 1978) and the original MABC (Henderson and Sugden 1992). Tan and colleagues, who used a clinical sample, found better agreement between the MAND and MABC in determining motor impairment. All three tests are considered to be based on the Normative Functional Skills approach (Wilson 2005), that is, they focus on the outcome of functional skills, and hence it would be expected that they would show good agreement. However, Brantner and colleagues, using a community sample, also failed to find strong agreement between the MAND and the MABC. Even with subtests that on face validity suggested similar motor skills (e.g., MAND Jumping and MABC Jumping over Cord), only medium correlations were found. 
Given such variability in outcome, which tests are the most suitable to use? In a recent review of movement skill assessment tools for preschool children, Cools and colleagues (2009) argued that the test to be used needs to be chosen in relation to the circumstance in which it is to be used. This would include the test purpose, which may be the clinical assessment of the child, assessment of an intervention which would require follow-up measures, or for research purposes in a community sample. Each test described above would be appropriate for different purposes. The other issue that needs to be considered is whether a general measure of motor performance is required or is there need to investigate a specific aspect of motor performance.

\section{Measuring Specific Performance Deficits}

Motor impairment can be quite specific. In some children, the impairment may be quite extensive involving a wide range of motor deficits, suggesting the disruption of many interconnected brain regions. In others it may only be related to difficulties in balance or locomotion (usually termed gross motor skills), or it may only affect manual skills such as drawing or using scissors (usually termed fine motor skills). More complex skills such as handwriting (grapho-motor ability) or ball skills may also be affected. This heterogeneity is not surprising given that these different skills (e.g., walking, postural adjustment, finger or arm movements) “all involve different specialized motor systems” (Carlson 2010, p. 273).

Movements are directly controlled by the primary motor cortex through two descending tracts, the ventromedial group and the lateral group. Table 1 lists the major motor pathways of these two tracts, and the muscle groups and functions they control. The cerebellum is also important for motor control. For example, the lateral zone of the cerebellum is linked with the planning of complex timed movement sequences, such as ball skills and other rapid, skilled movements (Carlson 2010). The reticular formation, comprising 
nuclei in the medulla, pons and midbrain is important in postural control and locomotion, and the basal ganglia have been linked with severe motor deficits such as Parkinson's disease which results in a loss or slowness of movement and Huntington's disease which causes uncontrollable jerky movements. This suggests that the basal ganglia are important in regulating smooth, slow movements (Carlson 2010). Assessment of specific motor skills may therefore provide some indication of where possible deficits originate.

Insert table 1 about here

Gross and fine motor skills are assessed separately in several of the assessment tools described above, such as the PDMS-2 which provides a separate quotient for gross motor, fine motor and total motor scores. Although the MAND has separate gross and fine motor scores, the psychometric properties for these subtests were based on a small sample of intellectually disabled adults. Consequently, the interpretation of the MAND subscale scores should be treated with caution, even though the concept of fine and gross motor skills may remain clinically useful. The BOT-2 derives four composite standard scores labelled fine manual control, manual coordination, body coordination and strength and agility, whereas the MABC-2 has three subtests, dynamic and static balance (often considered a measure of gross motor performance), manual skills (considered a measure of fine motor performance), and ball skills.

Largo and colleagues (2001) argue that the measure of manual skills in tests such as the MABC-2 are complex, such as cutting paper with scissors, and are therefore measuring non-motor skills involving considerable sensory processing. They suggest that these tests are suitable to assess functional skills, but an assessment tool such as the Zurich Neuromotor Assessment which individually assesses a range of timed movements (e.g., peg board, repetitive and sequential finger movements), is more clinically relevant as it appears that "timed performances of various motor tasks are not equally affected by neurological 
disturbances" (p. 442). They provided separate centile curves for these timed movements using a large sample of children in Zurich, including 106 kindergarten/preschool children.

Ball skills are considered a "demanding and complex motor task" (van Waelde et al., 2003, p.259) involving visual and kinaesthetic integration, appropriate timing and balance and considerable attentional demands. Van Waelde et al. (2003) argue that the ball skill tasks found in assessments such as the PDMS, BOTMP and MABC have not demonstrated adequate reliability at the test item level, and as a result they produced a standardised short ball catching test for children aged 7 to 9 years. However, there appears to be no comparable test for pre-school children.

Several tests have been designed to evaluate gross motor performance. For example, the Körperkoordination für kinder (KTK) quantitatively assesses dynamic balance skills in children aged between 5 and 14 years (Kiphard and Schilling 2007). As it takes around 20 minutes to administer and has excellent reliability it is considered very useful as a screening instrument to identify balance problems. However, Blank et al. (2012) warn that despite a recent version in 2007, the test norms were not updated from the original ones developed in 1973-74, a cause for concern.

The Test of Gross Motor Development-second edition (TGMD-2) uses skill-specific performance criteria to assess both object control (for example kick, overhand throw) and locomotor skills (run, hop) in children aged between 3 and 10 years (Ulrich 2000). This information is useful for developing targeted intervention programs, identifying children who need some additional instruction, and evaluating the success of teaching programs at an individual or group level. Slater and colleagues (2010) rated this test highly, ranking it equal first with the MABC-2.

A complex movement skill that is difficult to measure is handwriting. At the preschool age, handwriting skills have not developed, but at this level, it is important to develop 
handwriting readiness or pre-writing skills (van Hartingsveldt et al. 2011). It may be possible to identify a deficit in handwriting readiness through poor performance on fine motor tasks as there is extensive evidence of a relationship between fine motor difficulties and handwriting skill (e.g., Smits-Engelsman, Niemeijer and Van Galen 2001). Others, however, argue that the problem is more complex. For example, Volman, van Schendel and Jongmans (2006) suggested two different mechanisms may be responsible for hand-writing quality in children, fine motor control and visuo-motor integration. Hence, a test that covers this complexity is needed to assess pre-writing skills. In an extensive review of assessment tools for children aged 5 and 6 years, van Hartingsveldt identified 12 assessment tools that could assess handwriting readiness. They argued that only one test fulfilled the requirements of the Taxanomic Code of Occupational Performance for handwriting readiness. This was the School version of the Assessment of Motor and Process Skills (School-AMPS). Despite this, it fails to evaluate visual motor integration, which suggests a need to incorporate several tests when assessing handwriting readiness. The BOT-2, for example assesses both fine motor coordination and visual motor integration and was found to have the best psychometric properties of the 12 assessment tools identified. However, this was criticised for not being an occupation based assessment, that is, based on a real-life situation. Overall, more research is needed to determine the most suitable way of assessing this important skill at the preschool age.

\section{Recommendations}

The previous sections demonstrate clearly that the rate of development in the early years is not linear and varies considerably depending on the interaction between biological and environmental factors. If a lower score is obtained on motor assessments this could be the result of a range of factors contributing to developmental delay or may be due to a motor 
impairment. Therefore, if a child performs poorly on an assessment does he or she have a motor disability or is it simply late development (Blank et al. 2012), lack of opportunity or having a bad day? A study by Pless, Carlsson, Sundelin and Persson (2002) identified 37 preschool children aged 5-6 years with motor difficulties, but then on reassessment at age 7-8 years only 20 of these children showed definite motor problems. Of these 20,15 (out of 19) had definite problems at the initial testing and the remaining 5 (out of 18) were considered borderline at the initial testing phase. Level of severity appears to be an indicator of motor disability later on, a finding supporting previous studies that have investigated assessment at preschool and 10 years on (Cantell, Smyth and Ahonen 1994; Losse, Henderson, Elliman, Hall, Knight and Jongmans 1991).

In a recent review by Blank et al. (2012), several recommendations were made in terms of the assessment of motor ability in children 5 years and younger. Apart from the issue of misdiagnosis due to delayed development, the authors suggested that the reliability of the tests may be affected by the young child's lack of motivation or cooperation. However, assessment tools have proven to be reliable at this age, provided the child can engage appropriately with the testing process (e.g., Smits-Engelsman et al 2011). The recommendation for assessing pre-school children (3-5 years) was to only consider children who have a marked delay at their initial assessment (less than the $5^{\text {th }}$ percentile) and reassess after a minimum of 3 months following the initial assessment. Shorter assessment rates would not be recommended due to possible practice effects (Blank et al 2012).

This raises an additional issue in relation to assessment. Marked delay above is defined as 'less than the $5^{\text {th }}$ percentile'. The MABC-2, for example has a cut-off at the $15^{\text {th }}$ percentile for children described as at risk, and at the 5th percentile for definite motor impairment. The MAND has three cut-off levels for mild, moderate and severe disorder. Therefore, it would be recommended that children with definite or severe problems (usually 
within the $5^{\text {th }}$ percentile) should have immediate intervention, whereas those in the borderline range need to be carefully monitored. However, because of the heterogeneity of movement disorders, it is possible that a general motor assessment score that is in the at risk category may not capture a more specific deficit (Geuze et al. 2001) that is quite severe, as the scores are summed for the range of motor skills assessed. Therefore, it is essential to examine the test items or subtests to determine if there is a specific deficit or delay. If this is the case then further testing of this particular skill is recommended. Furthermore, a recommendation by Blank and colleagues (2012) is that once a child has been identified with a condition like Developmental Coordination Disorder, specific areas of motor function should be assessed in order to classify children into the ICD subgroups of gross motor dysfunctions (F82.0) or fine motor dysfunctions (F82.1) or both.

A further consideration is the impact of other developmental disorders on motor assessment. For example, if a child who is being assessed for motor deficits also has ADHD, how does this impact on the assessment? Can a child who has attention problems or is hyperactive or impulsive be accurately assessed? The same applies to children with learning or language difficulties. It is important to understand how these other disabilities could impact on assessment and carefully monitor the child's performance to ensure that their motor ability is accurately assessed. A recently developed test by Vles, Kroes and Feron (2004), the Maastrichtse Motoriek Test (MMT), assesses fine and gross movement skills in children aged 5 to 6 years and also claims to be able to identify children at risk of ADHD.

Too often in the past, motor impairment has been attributed to the symptoms of other disorders such as ADHD (e.g., DSM-IV diagnosis of ADHD, APA 2000). However, given the cognitive, academic and social problems that have been linked with motor impairment it is essential that a dual diagnosis be given if children also have a motor impairment. One example relates to anxious and depressive symptoms which could be linked to either motor 
impairment or ADHD symptomatology. Evidence suggests that both are equally important to consider (Piek et al 2007).

\section{Intervention Approaches}

If a child is identified with severe or definite motor problems then immediate intervention is recommended. However, what is effective intervention for pre-school aged children? Ideally, one on one therapy with health practitioners such as physiotherapists, occupational therapists or other movement specialists is considered the most effective treatment approach as it ensures that the intervention targets the specific deficits identified in each child. The type of intervention administered between and within each type of therapy is often eclectic, incorporating features of different types of approaches which can be adapted to suit the needs of the child. Hillier (2007) reviewed a variety of different intervention approaches available to children with motor learning difficulties and found that regardless of the type of intervention "what is trained is what is improved, whether it be sensory based or motor skill based “ (p. 9).

Physiotherapy in school-aged children with motor deficits has been found to be effective, provided the treatment is intensive and carried out by an experienced therapist (Schoemaker, Hijlkema and Kalverboer, 1994). Occupational therapy too has been found to be effective, particularly newer therapy models such as the Cognitive Orientation to daily Occupational Performance (CO-OP) which involves a problem-solving approach utilising cognitive strategies enabling children to achieve their functional goals (Polatajko, Mandich, Miller and Macnab, 2001). There are also other types of movement therapy available, which differ slightly from traditional models of therapy, and tend to concentrate on skills needed in daily living and for academic achievement, such as the Unigym program offered in Western 
Australia, using a task-specific approach centred on the development of fundamental movement skills.

While one on one therapy does offer individualised programming, group settings can also beneficial in certain situations, particularly for the development of social skills which can often be deficient. It is important however that the severity of movement difficulties, level of interaction of the child with other members of the group and goals of the intervention be all carefully considered (Blank et al., 2012). What works well for one child may not necessarily work well for another, so it is important that children are well matched in group settings to ensure that movement and social outcomes are optimised. These issues are taken into account with the Animal Fun program (Piek et al. 2010) which is a universal program for pre-primary children administered by teachers to the whole class. This program includes modules designed to promote both gross and fine motor development as well as social/emotional development.

It is important for intervention to extend beyond the therapy sessions. As Sugden and Chambers (2003) point out, access to therapists can be difficult for a number of reasons, and other approaches need to be considered. They demonstrated the importance that family and teachers can make in assisting with the development of children's motor skills. Simple activities such as re-enforcement of techniques used in therapy sessions and through home exercises are important, along with an open line of communication between the therapists working with the child, their families and teachers. It is important that a child has the opportunity to develop a broad array of movement skills, so they can fully engage in all aspects of their life, including those needed at home, school and in the playground.

\section{Conclusion}


It is clear that early identification of motor impairment, even in less severe disorders such as DCD, is crucial. It is needed in order to provide appropriate intervention, not only to improve motor skills, but also to prevent or reduce health, academic, and psychosocial problems associated with poor motor ability. Also, it is clear that children may have specific motor deficits or delays that need to be addressed, and without appropriate assessment it is difficult to know these specific problems. Not only is this important to improve the child's motor ability, but recent research has highlighted the importance of identifying specific motor deficits because of their links with other problems. For example, recent research in an adolescent sample demonstrated that ball skills, but not manual dexterity or balance, was linked with working memory and academic performance, possibly due to the importance of the cerebellum in all of these processes (Rigoli, Piek, Kane and Oosterlaan, accepted subject to revision). Furthermore, in the same sample, aiming and catching and balance skills (but not manual dexterity) were related to psychosocial factors such as self-perceptions, anxiety and depression (Rigoli, Piek and Kane 2012).

In conclusion, although there are many assessment tools available, it is important to determine the most appropriate tools to use. We have provided an overview of the most commonly used tools, and have also indicated where further research is needed.

Unfortunately, there is much to be done as the importance of motor development in all aspects of a child's development has only recently been recognised.

\section{Acknowledgments}

We wish to thank Daniela Rigoli for her assistance with the literature search for this review, and her valuable comments on an earlier draft of this manuscript. 


\section{References}

Alloway, T.P. (2007). Working memory, reading, and mathematical skills in children with developmental coordination disorder. Journal of Experimental Child Psychology, 96, 20-36.

American Psychiatric Association. (2000). Diagnostic and statistical manual of mental disorders: Text revision ( $4^{\text {th }}$ ed.). Washington, DC: Author.

Anastasi, A. (1981). Sex differences: Historical perspectives and methodological implications. Developmental Review, 1, 187-206.

Barnett, A. L. (2008). Motor assessment in developmental coordination disorder: from identification to intervention. International Journal of Disability, Development and Education, 55(2), 113-129.

Blank, R., Smits-Engelsman, B., Polatajko, H., \& Wilson, P. (2012). European Academy for Childhood Disability (EACD): Recommendations on the definition, diagnosis and intervention of developmental coordination disorder (long version). Developmental Medicine \& Child Neurology, 54, 54-93. DOI:10.1111/j.1469-8749.2011.04171.x

Bower, T.G.R. (1977). A primer of infant development. San Fransisco: Freeman.

Brantner, S. Piek, J.P. \& Smith, L.M. (2009) Evaluation of the Validity of the MAND in Assessing Motor Impairment in Young Children. Rehabilitation Psychology, 54, 413421.

Brown, T. \& Lalor, A. (2009). The Movement Assessment Battery for Children - Sescond Edition (MABC-2): A review and Critique. Physical a\& Occupational Therapy in Pediatrics, 29(1), 86-103).

Bruininks, R. H. (1978). The Bruininks - Oseretsky Test of Motor Proficiency examiner's manual. Circle Pines, MN: American Guidance Service. 
Bruininks, R.H. \& Bruininks, B.D. (2005). Test of Motor Proficiency. $2^{\text {nd }}$ Edition. Manual: AGS Publishing. Circle Pines.

Burton, A. W., \& Miller, D. E. (1998). Movement skill assessment. Champaign, IL: Human Kinetics.

Burton, A.W. \& Rodgerson, R.W. (2001). New Perspectives on the Assessment of Movement Skills and Motor Abilities. Adapted Physical Activity Quarterly, 18, 347-365.

Cairney, J., Veldhuizen, S., \& Szatmari, P. (2010). Motor coordination and emotionalbehavioral problems in children. Current Opinion in Psychiatry, 23, 324-329.

Cantell, M. H., Smyth, M. M., \& Ahonen, T. P. (1994). Clumsiness in adolescence: Educational, motor, and social outcomes of motor delay detected at 5 years. Adapted Physical Activity Quarterly, 11 (2), 115-129

Capute, A. J., Shapiro, B. K., Palmer, F. B., Ross, A., \& Wachtel, R. C. (1985). Normal gross motor development: The influences of race, sex and socio-economic status. Developmental Medicine \& Child Neurology, 27, 635-643.

Carlson, N. R. (2010). Physiology of Behavior (10th ed.). Boston: Allyn \& Bacon.

Casey, B.J., Tottenham, N., Liston, C., \& Durston, S. (2005). Imaging the developing brain: what have we learned about cognitive development? TRENDS in Cognitive Sciences, 9(3), 104-110.

Chia, L.C., Guelfi, K.J, \& Licari, M.K. (2009). A comparison of the oxygen cost of locomotion in children with and without developmental coordination disorder. Developmental Medicine \& Child Neurology, 52, 251-255.

Chugani, H.T. (1994). Development of regional brain glucose metabolism in relation to behaviour and plasticity. In G. Dawson and K. Fischer (Eds.). Human behaviour and the developing brain (pp. 153-175). New York: Guilford Press. 
Chugani, H.T. (1998). A critical period of brain development: Studies of cerebral glucose utilization with PET. Preventive Medicine, 27, 184-188.

Chugani, H.T., Phelps, M.E., \& Mazziotta, J.C. (1987). Positron emission tomography study of human brain development. Annals of Neurology, 22, 487-497.

Cools, W., De Martelaer, K., Samaey, C., \& Andries, C. (2009). Movement skill assessment of typically developing preschool children: A review of seven movement skill assessment tools. Journal of Sports Science and medicine, 8, 154-168.

De Bellis, M.D., Keshavan, M.S., Beers, S.R., Hall, J., Frustaci, K., Masalehdan, A., et al. (2001). Sex Differences in Brain Maturation during Childhood and Adolescence. Cerebral Cortex, 11, 552-557.

Deitz, J. C., Kartin, D., \& Kopp, K. (2007). Review of the Bruininks-Oserestsky Test of Motor Proficiency, Second edition (BOT-2). Physical and Occupational Therapy in Pediatrics, 27(4), 87-102.

Dekaban., A.S. (1978). Changes in brain weights during the span of human life: Relation of brain weights to body heights and body weights. Annals of Neurology, 4 (4), 345-356.

Dewey, D., Cantell, M., \& Crawford, S.G. (2007). Motor and gestural performance in children with autism spectrum disorders, developmental coordination disorder and/or attention deficit hyperactivity disorder. Journal of the International Neuropsychological Society, $13,246-256$.

Dewey, D., Wilson, B. N., Crawford, S. G., \& Kaplan, B. J. (2000). Comorbidity of developmental coordination disorder with ADHD and reading disability. Journal of the International Neuropsychological Society, 6, 152.

Dyck, M., Piek, J.P., Hay, D.A., Smith, L. \& Hallmayer, J. (2006) Are Abilities Abnormally Interdependent in Children with Autism? Journal of Clinical Child and Adolescent Psychology, 35, 20-33. 
Engel-Yeger, B., Rosenblum, S., \& Josman, N. (2010). Movement Assessment Battery for Children (M-ABC): Establishing construct validity for Israeli children. Research in Developmental Disabilities, 31(1), 87-96.

Erez, O., Gordon, C.R., Sever, J., Sadeh, A., \& Matti, M. (2004). Balance dysfunction in childhood anxiety: Findings and theoretical approach. Anxiety Disorders, 18, 341-356.

Fawcett, A. J., \& Nicholson, R. I. (1995). Persistent deficits in motor skill of children with dyslexia. Journal of Motor Behavior, 27, 235-240.

Fietzek, U.M., Heinen, F., Berweck, S., Maute, S., Hufschmidt, A., Schulte-Mönting, J., et al. (2000). Development of the corticosponal system and hand motor function: central cinduction times and motor performance tests. Developmental Medicine \& Child Neurology, 42, 220-227.

Folio, M.R., \& Fewell, R.R. (1983). Peabody Developmental Motor Scales and Activity Cards. DLM teachers resources, Allen-Texas.

Folio, M.R., \& Fewell, R.R. (2000). Peabody Developmental Motor Scales (PDMS-2). Austin, TX: Pro-ed.

Gallahue, D. L., \& Ozmun, J. C. (2002). Understanding motor development: Infants, children, adolescents, adults ( $5^{\text {th }}$ Edition). Singapore: McGraw Hill.

Geuze, R. H., Jongmans, M. J., Schoemaker, M. M., \& Smits-Engelsman, B. C. M. (2001). Clinical and research diagnostic criteria for developmental coordination disorder: A review and discussion. Human Movement Science, 20, 7-47.

Goodway, J. D., Crowe, H., \& Ward, P. (2003). Effects of motor skill instruction on fundamental motor skill development. Adapted Physical Activity Quarterly, 20, 298 314. 
Gottlieb, G. (2001). The relevance of developmental-psychobiological metatheory to developmental neuropsychology. Developmental Neuropsychology, 19 (10), 1-9.

Greenough, W. T., \& Black, J. E. (1992). Induction of brain structure by experience: Substrates for cognitive development. In M. Gunnar \& C. Nelson (Eds.), Minnesota Symposia on Child Psychology. Vol. 24, Developmental Behavioral Neuroscience (p. 155-200).

Groeschel, S., Vollmer, B., King, M.D., \& Connelly, A. (2010). Developmental changes in cerebral grey and white matter volume from infancy to adulthood. International Journal of Developmental Neuroscience, 28, 481-489.

Gutteridge, M. (1939). A study of motor achievements of young children. Archives of Psychology, 244, 1-178.

Haas, G., \& Diener, H.C. (1988). Development of stance control in children. In B. Amblard, A. Berthoz, \& F. Clarac (Eds). Posture and gait: Development, adaptation and modulation (pp. 49-58). Amsterdam: Elsevier.

Hamilton, A. (1981). Nature and nurture: Aboriginal child-rearing in north-central Arnhem land. Canberra: Australian Institute of Aboriginal Studies.

Hands, B., \& Larkin, D. (1997). Gender bias in measurement of movement. ACHPER Healthy Lifestyles Journal, 44(1), 12-16.

Hands, B., \& Larkin, D. (2002). Physical Fitness and Developmental Coordination Disorder. In S. A. Cermak \& D. Larkin (Eds.), Developmental Coordination Disorder. San Diego, CA: Thomson Learning.

Hands, B., \& Larkin, D. (2006). Physical fitness of children with motor learning difficulties. European Journal of Special Needs Education, 21(4), 447-456.

Hands, B., Larkin, D., Parker, H., Straker, L., \& Perry, M. (2009). The relationship among physical activity, motor competence and health-related fitness in 14-year-old 
adolescents. Scandinavian Journal of Medicine and Science in Sports, 18, 655-663. doi: 10.1111/j.1600-0838.2008.00847.x

Henderson, S. E., \& Sugden, D. A. (1992). Movement Assessment Battery for Children: Manual. London: The Psychological Corporation Ltd.

Henderson, S. E., Sugden, D. A., \& Barnett, A. L. (2007). Movement Assessment Battery for Children -2 second edition. London: Harcourt Assessment.

Hillier, S. (2007). Intervention for children with developmental coordination disorder: A systematic review. The Internet Journal of Allied Health Sciences and Practice, 5, 1-11.

Johnson, M.H. (2003). Development of Human Brain Functions, 54, 1312-1316.

Keogh, J. \& Sugden, D. (1985). Movement skill development. New York: Macmillan.

Kiphard, E.J., \& Schilling, F. (2007). Körperkoordinationtest für Kinder 2, überarbeitete und ergänzte Auflage. Beltz test, Weinheim.

Kurdek, L. A., \& Sinclair, R. J. (2001). Predicting reading and mathematics achievement in fourth-grade children from kindergarten readiness scores. Journal of Educational Psychology. 93, 451-455.

Largo, R.H., Caflisch, J.A., Hug, F., Muggli, K., Molnar, A.A., Molinari, L., et al. (2001). Neuromotor development from 5 to 18 years. Part 1: timed performance. Developmental Medicine \& Child Neurology, 32, 436-43.

Liu, Y., Metems, T., Absil, J., De Maertelaer, V., Balériaux, D., David, P., et al. (2011). Gender Differences in Language and Motor-Related Fibers in a Population of healthy Preterm Neonates at Term-Equivalent Age: A diffusion Tensor and Probablistic Tractography Study. American Journal of Neuroradiology, 32, 2011-16. 
Livesey, D., Coleman, R., \& Piek, J. (2007). Performance on the Movement assessment Battery for children by Australian 3- to 5-year-old children. Child care, health and development, doi:10.1111/j.1365-2214.2007.00733.x.

Losse, A., Henderson, A. E., Elliman, D., Hall. D., Knight, E., \& Jongmans, M. (1991). Clumsiness in children - Do they grow out of it? A ten-year follow-up study. Developmental Medicine and Child Neurology, 33, 55-68.

Mandich, A. D., Polatajko, H. J., \& Rodger, S. (2003). Rites of passage: Understanding participation of children with developmental coordination disorder. Human Movement Science, 22, 583-595.

McCarron, L. T. (1997). MAND McCarron Assessment of Neuromuscular Development: Fine and gross motor abilities (Rev. ed.). Dallas, TX: Common Market Press.

McPhillips, M., \& Jordan-Black, J. (2007). The effect of social disadvantage on motor development in young children: a comparative study. Journal of Child Psychology and Psychiatry, 48, 1214-1222.

Miyahara, M. \& Piek, J.P. (2006) Self-Esteem of Children and Adolescents with Physical Disabilities: Quantitative Evidence from Meta-Analysis. Journal of Developmental and Physical Disabilities, 18, 219-234.

Morris, A., Williams, J., Atwater, A., \& Wilmore, J. (1982). Age and sex differences in motor performances of 3 through to 6 year old children. Research Quarterly for Exercise and Sport, 53(3), 214-221.

Murray, G. K., Veijola, J., Moilanen, K., Miettunen, J., Glahn, D. C., Cannon, T. D., et al. (2006). Infant motor development is associated with adult cognitive categorisation in a longitudinal birth cohort study. Journal of Child Psychology and Psychiatry, 47, 25 29. 
Pearsall-Jones, J.G., Piek, J.P., Rigoli, D., Martin, N., \& Levy, F. (2011) Motor disorder and anxiety and depressive symptomatology: A monozygotic co-twin control approach. Research in Developmental Disabilities, 32, 1245-1252

Pedersen, A.V., Sigmundsson, H., Whiting, H.T.A., \& Ingvaldsen, R.P. (2003). Sex differences in lateralisaton of fine manual skills in children. Experimental Brain Research, 149, 249-251.

Perrin, J.S., Leonard, G., Perron, M., Pike, G.B., Pitiot, A., Richer, L., et al. (2009). Sex differences in the growth of white matter during adolescence, Neuroimage, 45, 10551066.

Piek, J.P. (2006). Infant Motor Development. Champaign, IL: Human Kinetics.

Piek, J.P., Barrett, N.C., Smith, L.M., Rigoli, D., \& Gasson, N. (2010) Do Motor Skills in Infancy and Early Childhood Predict Anxious and Depressive Symptomatology at School Age? Human Movement Science, 29, 777-786.

Piek, J.P., Bradbury, G.S., Elsley, S.C., \& Tate, L. (2008). Motor coordination and socialemotional behaviour in preschool aged children. International Journal of Disability, Development and Education, 55, 143-151.

Piek, J. P., Dawson, L., Smith, L. M., \& Gasson, N. (2008). The role of early fine and gross motor development on later motor and cognitive ability. Human Movement Science. 27, 668-681.

Piek, J.P., Gasson, N., Barrett, N.C., \& Case, I. (2002). Limb and gender differences in the development of coordination in early infancy. Human Movement Science, 21, 621639.

Piek, J.P., Rigoli, D., Pearsall-Jones, J.G., Martin, N.C., Hay, D.A., Bennett, K.S., \& Levy, F. (2007). Depressive Symptomatology in Child and Adolescent Twins with Attention 
Deficit Hyperactivity Disorder and/or Developmental Coordination Disorder. Twin Research and Human Genetics, 10, 587-596

Piek, J.P., Straker, L.M., Jensen, L., Dender, A., Barrett, N.C., McLaren, S. Roberts, C, Reid, C., Rooney, R., Packer, T., Bradbury, G. \& Elsley, S. (2010). Rationale, design and methods for a randomised and controlled trial to evaluate "Animal Fun" - a program designed to enhance physical and mental health in young children. BMC Pediatrics, 10,78

Pitcher, T.M., Piek, J.P., \& Hay, D.A. (2003) Fine and gross motor ability in boys with attention deficit hyperactivity disorder. Developmental Medicine \& Child Neurology, $45,525-535$

Pless, M., Carlsson, M., Sundelin, C. \& Persson, K. (2002). Preschool children with developmental coordination disorder: a short-term follow-up of motor status at seven to eight years of age. Acta Paediatrica, 91, 521-528.

Polatajko, H.J., Mandich, A.D., Miller, L.T., \& Macnab, J.J. (2001). Cognitive orientation to daily occupational performance (CO-OP: part II - the evidence. Physical \& Occupational Therapy in Pediatrics, 20, 83-106.

Provine, R.R. (1993). Natural priorities for developmental study: Neuroembryological perspectives of motor development. In A.F. Kalverboer, B. Hopkins, \& R. Geuze (Eds). Motor development in early and later childhood: Longitudinal approaches (pp. 1-73). Cambridge: Cambridge University Press.

Rasmussen, P., \& Gillberg, C. (2000). Natural outcome of ADHD with DCD at age 22 years: A controlled longitudinal community based study. Journal of the American Academy of Child and Adolescent Psychiatry, 39, 1424-1431.

Rigoli, D., Piek, J.P. \& Kane, R. (2012) Motor skills and psychosocial correlates in a normal adolescent sample. Pediatrics, 129, e892-e900. doi:10.1542/peds.2011-1237 
Rigoli, D., Piek, J.P., Kane, R., \& Oosterlaan, J. (accepted subject to minor revision) Motor skills, working memory and academic achievement in a normal population of adolescents: testing a mediation model. Archives of Clinical Neuropsychology

Rose, B., Larkin, D., \& Berger, B. G. (1997). Coordination and gender influences on the perceived competence of children. Adapted Physical Activity Quarterly, 14 (3), 210 221.

Schoemaker, M.M., Hijlkema, M.G.J., \& Kalverboer, A.F. (1994). Physiotherapy for clumsy children: An evaluation study. Developmental Medicine and Child Neurology, 36, 143 155.

Schott, N., Alof, V., Hultsch, D., \& Meermann, D. (2007). Physical fitness in children with developmental coordination disorder. Research Quarterly for Exercise and Sport, 78, $438-450$.

Sigurdsson, E., van Os, J., \& Fombonne, E. (2002). Are impaired childhood motor skills a risk factor for adolescent anxiety? Results from the 1958 U.K. birth cohort and the national child development study. American Journal of Psychiatry, 159, 1044-1066.

Silman, A., Cairney, J., Hay, J., Klentrou, P., \& Faught, B. E. (2011). Role of physical activity and perceived adequacy on peak aerobic power in children with developmental coordination disorder. Human Movement Science, 30(3), 672-681.

Skinner, R.A. \& Piek, J.P. (2001) Psychosocial implications of poor motor coordination in children and adolescents, Human Movement Science, 20, 73-94 .

Slater, L.M., Hillier, S.L., \& Civetta, L.R. (2010). The Clinimetric Properties of Performance-Based Gross Motor Tests Used Children with Developmental 
Coordination Disorder: A Systematic Review. Pediatric Physical Therapy, DOI: 10.1097/PEP.0b013e3181dbeff0.

Smits-Engelsman, B.C., Niemeijer, A.S., \& Van Galen, G.P. (2001). Fine motor deficiencies in children diagnosed as DCD based on poor grapho-motor ability. Human Movement Science, 20, 161-182.

Smits-Engelsman, B.C.M., Niemeijer, A.S., \& van Waelvelde, H. (2011). Is the Movement Assessment Battery for Children- $2^{\text {nd }}$ edition a reliable instrument to measure motor performance in 3 year old children? Research in Developmental Disabilities, 32, $1370-1377$.

Smyth, M. M., \& Anderson, H. I. (2000). Coping with clumsiness in the school playground: Social and physical play in children with coordination impairments. British Journal of Developmental Psychology, 18, 389-413

Sowell, E.R., Thompson, P.M., Leonard, C.M., Welcome, S.E., Kan, E., \& Toga, A.W. (2004). Longitudinal Mapping of Cortical Thickness and Brain Growth in Normal Children. The Journal of Neuroscience, 24(38), 8223-8231.

Spironello, C., Hay, J., Missiuna, C., Faught, B.E., \& Cairney, J. (2010). Concurrent and construct validation of the short form of the Bruininks-Oseretsky Test of Motor Proficiency and the Movement-ABC when administered under field conditions: implications for screening. Child: Care, Health and Development, 36(4), 499-507.

Sugden, D.A. \& Chambers, M. (2003). Intervention in children with Developmental Coordination Disorder: the role of parents and teachers. British Journal of Educational Psychology, 73, 545-561. 
Super, C.M. (1976). Environmental effects on motor development: The case of "African infant precocity". Developmental Medicine \& Child Neurology, 18, 561-567.

Sveistrup, H., \& Woollacott, M. (1996) Longitudinal development of the automatic response in infants. Journal of Motor Behavior, 28, 58-70.

Sveistrup, H., \& Woollacott, M. (1997) Practice modifies the developing automatic postural response. Experimental Brain Research, 114, 33-43.

Tan, S. K., Parker, H. E., \& Larkin, D. (2001). Concurrent validity of motor tests used to identify children with motor impairment. Adapted Physical Activity Quarterly, 18 (2), $168-182$.

Tau, G.Z., \& Peterson, B.S. (2010). Normal Development of Brain Circuits. Neuropsychopharmacology, 35, 147-168.

Thomas, J.R., \& French, K.E. (1985). Gender differences across age in motor performance: A meta-analysis. Psychological Bulletin, 98, 260-282.

Touwen, B. (1976). Neurological Development in Infancy. London: William Heinemann Medical Books.

Ulrich, D.A. (2000). Test of Gross Motor Development, $2^{\text {nd }}$ Ed. Examiner's Manual. Pro-ED. Inc, Austin Texas.

Van Hartingsveldt, M.J., De Groot, I.J.M., Aarts, P.B.M., \& Nijhuis-van der Sanden, M.W.G. (2011). Standardized tests of handwriting readiness: a systematic review of the literature. Developmental Medicine \& Child Neurology, 53, 506-515.

Van Waelvelde, H., De Weerdet, W., De Cock, P., \& Smits-Engelsman, B.C.M. (2003). Ball catching. Can it be measured? Physiotherapy Theory and Practice, 19, 259-267.

Vles, J.S.H., Kroes, M., \& Feron, F.J.M. (2004). MMT: Maastrichtse Motoriek Test. Pits BV, Leiden. 
Volman, M.J., van Schendel, B.M., \& Jongmans, M.J. (2006). Handwriting difficulties in primary school children: a search for underlying mechanisms. American Journal of Occupational Therapy, 60, 451-460.

Wilson, P.H. (2005). Practitioner review: Approaches to assessment and treatment of children with DCD: an evaluative review. Journal of Child Psychology and Psychiatry, 46, 806-823. 


\section{Figure captions}

Fig. 1.

Annualised rate of growth in the cerebral cortex in 5-11 year olds. Red regions indicate regions with greatest annual growth. [Reprinted with permission from Sowell, E.R., Thompson, P.M., Leonard, C.M., Welcome, S.E., Kan, E., \& Toga, A.W. (2004). Longitudinal Mapping of Cortical Thickness and Brain Growth in Normal Children. The Journal of Neuroscience, 24(38), 8223-8231, Figure 5, page 8227.]

Fig 2.

Sensori-motor and language related tracts were shown on b0 images in a healthy preterm girl born at 31 weeks GA and imaged at 37 weeks GA (A-C) and in a boy born at 30 weeks GA and imaged at 37 weeks GA (D-F). Axial (A, D) and coronal (B, E) images showed the CST (dark green) and the STR (motor STR in yellow-red and sensory STR in blue). Sagittal images (C, F) showed the fronto-parietal SLF (light green) and parieto-temporal SLF (pink). [reprinted with permission from Liu, Y., Metems, T., Absil, J., De Maertelaer, V., Balériaux, D., David, P., et al. (2011). Gender Differences in Language and Motor-Related Fibers in a Population of healthy Preterm Neonates at Term-Equivalent Age: A diffusion Tensor and Probablistic Tractography Study. American Journal of Neuroradiology, 32, 2011-16, Figure 1, page 2013.] 
Table 1.

The major motor pathways of the motor cortex for A. The Lateral Group, and B. the Ventromedial Group. Note: all terminate in the spinal cord except the corticobulbar tract which terminates in the cranial nerve nuclei: 5, 7, 9, and 10-12. (Adapted from N.R. Carlson, Physiology of Behavior, 10th edn., 2010, p. 277, Reprinted by permission of Pearson Education, Inc., Upper Saddle River, New Jersey.)

\section{A. LATERAL GROUP}

\begin{tabular}{|l|l|l|l|}
\hline & ORIGIN & MUSCLE GROUP & FUNCTION \\
\hline $\begin{array}{l}\text { Lateral } \\
\text { corticospinal } \\
\text { tract }\end{array}$ & $\begin{array}{l}\text { Finger, hand, and } \\
\text { arm region of the } \\
\text { motor cortex }\end{array}$ & $\begin{array}{l}\text { Fingers, hands and } \\
\text { arms }\end{array}$ & $\begin{array}{l}\text { Grasping and } \\
\text { manipulating objects }\end{array}$ \\
\hline Rubrospinal tract & Red nucleus & $\begin{array}{l}\text { Hands (not fingers), } \\
\text { lower arms, feet, and } \\
\text { lower legs }\end{array}$ & $\begin{array}{l}\text { Movement of } \\
\text { forearms and hands } \\
\text { independent from } \\
\text { that of the trunk }\end{array}$ \\
\hline $\begin{array}{l}\text { Corticobulbar } \\
\text { tract }\end{array}$ & $\begin{array}{l}\text { Face region of motor } \\
\text { cortex }\end{array}$ & Face and tongue & $\begin{array}{l}\text { Face and tongue } \\
\text { movements }\end{array}$ \\
\hline
\end{tabular}

\section{B. VENTROMEDIAL GROUP}

\begin{tabular}{|l|l|l|l|}
\hline & ORIGIN & MUSCLE GROUP & FUNCTION \\
\hline Vestibulospinal tract & Vestibular nuclei & Trunk and legs & Posture \\
\hline Tectospinal tract & Superior colliculi & Neck and trunk & $\begin{array}{l}\text { Coordination of eye } \\
\text { movements with } \\
\text { those of trunk and } \\
\text { head. }\end{array}$ \\
\hline $\begin{array}{l}\text { Lateral reticulospinal } \\
\text { tract }\end{array}$ & $\begin{array}{l}\text { Medullary reticular } \\
\text { formation }\end{array}$ & Flexor muscles of legs & Walking \\
\hline $\begin{array}{l}\text { Medial reticulospinal } \\
\text { tract }\end{array}$ & $\begin{array}{l}\text { Pontine reticular } \\
\text { formation }\end{array}$ & $\begin{array}{l}\text { Extensor muscles of } \\
\text { legs }\end{array}$ & Walking \\
\hline $\begin{array}{l}\text { Ventral corticospinal } \\
\text { tract }\end{array}$ & $\begin{array}{l}\text { Trunk and upper leg } \\
\text { region of motor } \\
\text { cortex }\end{array}$ & $\begin{array}{l}\text { Hands (not fingers), } \\
\text { lower arms, feet and } \\
\text { lower legs }\end{array}$ & $\begin{array}{l}\text { Locomotion and } \\
\text { posture }\end{array}$ \\
\hline
\end{tabular}


Fig 1

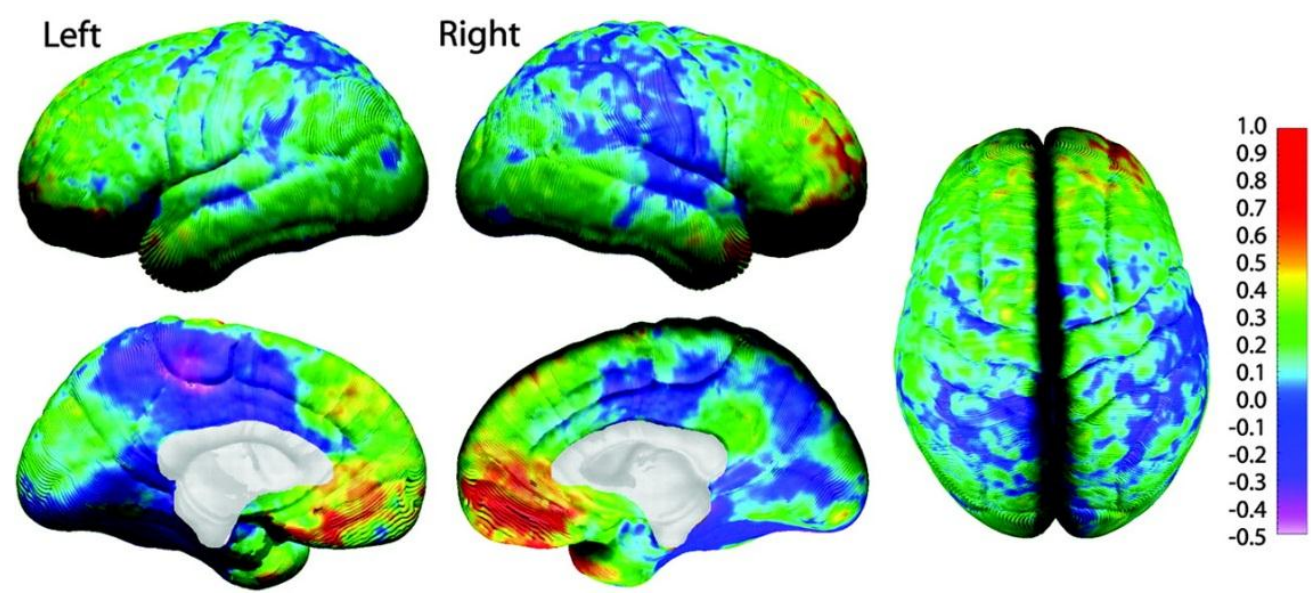


Fig 1

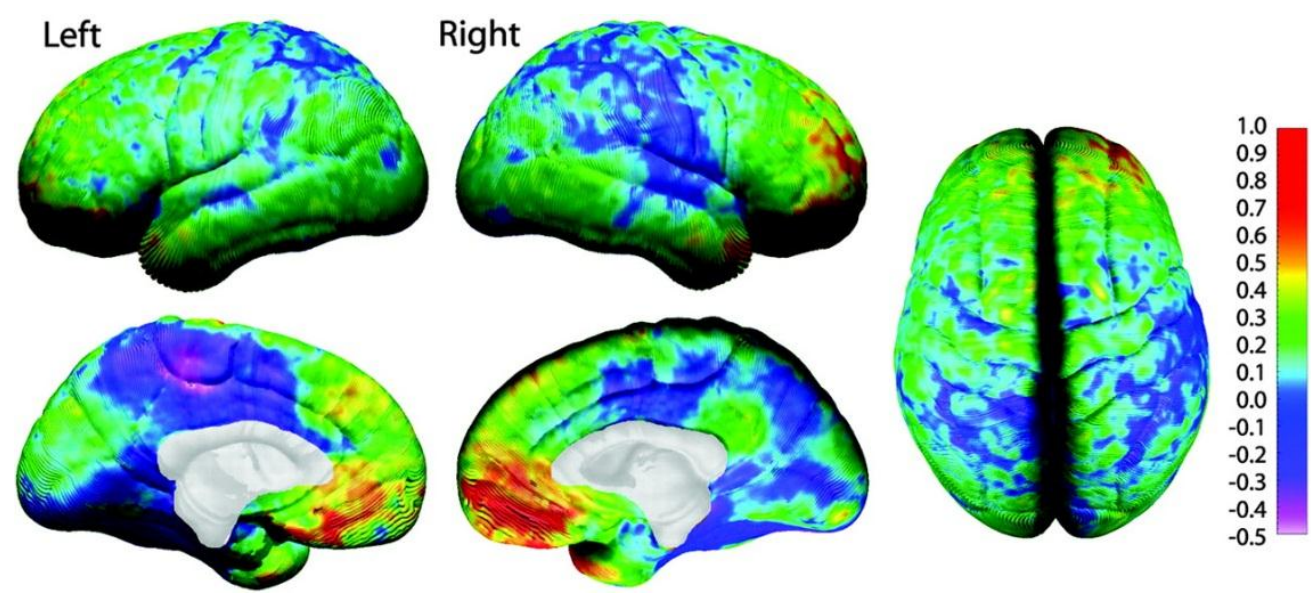




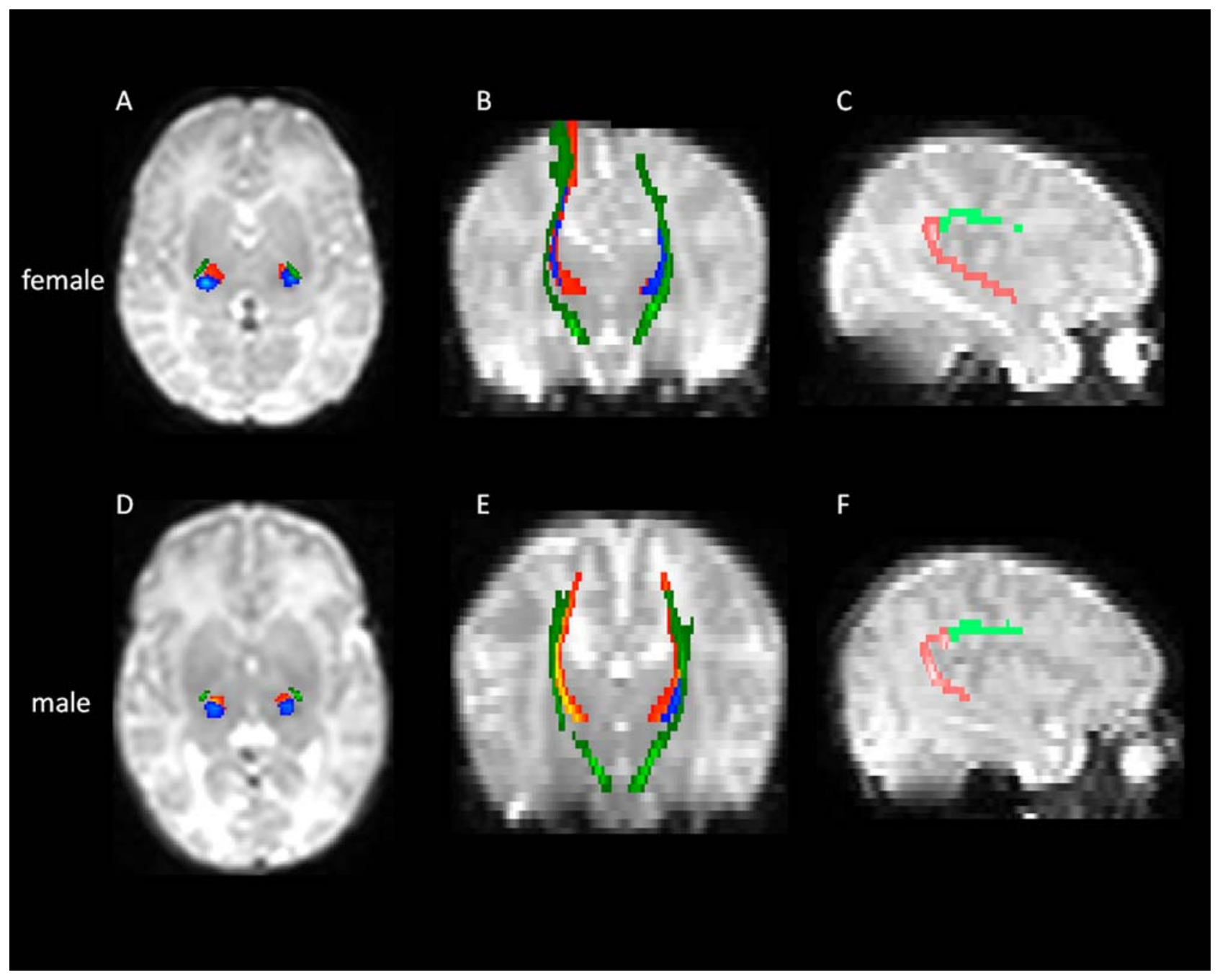

